\title{
The Pathway of COVID-19 Pandemic Fear: An Experience from General Practice, Germany Ulrich Freitag
}

\author{
"Nothing in life is to be feared, it is only to be understood. Now is the time to understand more, so that we \\ may fear less." - Marie Curie ${ }^{1}$
}

We have recently seen this passionate world stopped for months as if the nature has pressed a reset button. The World Health Organization (WHO) on December 31, 2019 received reports of patients with atypical pneumonia form Wuhan, Hubei Province, China caused by a new virus; Severe Acute Respiratory Syndrome Coronavirus 2 (SARS-CoV-2); currently designated as Coronavirus disease (COVID-19). ${ }^{2}$ Although it was already a major health issue in China in the beginning of 2020, German people and health practitioners thought that the situation is far away from Europe like Ebola or malaria in the history.

As the first case was reported from Munich on January 27, 2020, acquired during a professional contact with an asymptomatic Chinese partner, we were very inquisitive to recognize the first warning signs. ${ }^{3}$ Until the beginning of March 2020, general practitioners in Germany were still quite unworried. The health authorities had guided us to collect throat swabs only in clearly symptomatic patients in order not to overwhelm the test capacities. Soon the death rate started tolling and it was a state of "over-mortality" especially in old and chronically ill people as we experience every winter as a result of influenza related diseases. As we saw the pictures of trucks loaded with dead bodies from hospital to the crematoria through the press release in Italy, the fear became increasingly serious here.

The authorities were not prepared for the pandemic. Although they delayed at the beginning to react, the government was increasingly able to act at this point. They limited the spread of threat to the public and took initiatives in close cooperation with experts in good time. Nothing was closed completely. Manufacture of enough protective clothing and disinfectants was initiated. General hospitals were cleared for emergencies and all elective procedures were postponed. Provision of enough ventilators was made in the intensive care units. People with cold related symptoms were advised to stay at home. Those who couldn't go to work were provided salary on the basis medical certificate for up to 6 weeks.

The systematized medical faculty also acted. Test centers were set up in each community to screen patients suspected with COVID-19. Quarantine centers were established. At the general practitioners' office, which by the time were prepared with protective clothing and organizational changes such as separate entrances, distanced waiting areas, sneeze guards and isolated stations, suddenly had very little work because the patients with routine concerns avoided the clinics due to fear of infection. Our test laboratories were enormously provided with test kits for COVID-19, so that we could effectively test the suspected and hand over the local authority for robust contact tracing. For simple illnesses as cough, running nose and diarrhea, people took advice on the phone. Video consultation hours were introduced. We were quite worried for patients who would delay to present with myocardial infarction or stroke.

The recommendations of our government halted the public life to a standstill position, delaying the spread of the pandemic in Germany; as the recommendations were seriously commenced. Schools, kindergartens, religious institutions, sports centers, hotels and restaurants were all shut. All businesses and public meetings that did not serve the immediate supply were closed. E-learning and e-conferencing were encouraged. Necessary facilities with a social distancing of 1-2 meters always continued. As these measures were very well communicated and largely enlightened among general public, one can sing songs of a so far successful strategy which reasonably prevented the collapse of the German health care system. 
Of course, the economic and social lockdown had serious consequences. Nobody could predict the costs that families, households, businesses and the state will incur as a result of months of inactivity. Many earnings did shrunk, numerous companies and businesses could not recover despite government aid and the state has been in debt for many decades. In private life, we had to accept many restrictions including our habits, sporting, leisure, vacation, friends, and relatives including festivals which were strictly cancelled. Impatience was stirring here and there. In a population of 83 million people despite the relative low incidence of infections the restrictions did not loosen faster. The responsibilities for easing the restrictions were delegated to the federal states, districts and municipalities depending upon the case load. We gradually started getting more work in our doctor's clinic too, after the number of consultations had meanwhile dropped far below $50 \%$. Places, where local infection flared up, new restrictions were quickly imposed.

Awareness was attained that new cases were coming from places where social distancing was not complied with due to the situation (refugee accommodation or dormitories for migrant workers) or risks were taken out of ignorance (experienced by religious sects during their services or rallies where the distance requirement was deliberately disregarded) or where people thought they were in false security when meeting friends or relatives in guest or private rooms. The government acted rigorously upon them. The vast majority of the population now respects the laws for its restrictions.

We believe that there are many nations where the infection has not yet started. Our realization that education and complying with the distancing guidelines; is the current key to overcome the fear of this pandemic. However, this may vary according to the freedom and educational status of the country's population. At this point of clock, understanding this fact to overcome the fear of infection and death could be rewarding.

May this world be blessed soon with COVID-19 vaccine.

Dr. Med. Ulrich Freitag,

General Practitioner,

Consultant, General Medicine,

Ebsdorfergrund, Bortshäuser Str,

Germany.

\section{REFERENCES}

1. Mittal BR. From Editor's Desk. Indian J Nucl Med. 2018;33(Suppl 1):S1-S2.

2. Phelan AL, Katz R, Gostin LO. The Novel Coronavirus Originating in Wuhan, China: Challenges for Global Health Governance [published online ahead of print, 2020 Jan 30]. JAMA. 2020;10.1001/jama.2020.1097.

3. Rothe C, Schunk M, Sothmann P, Bretzel G, Froeschl G, Wallrauch C, et al. Investigation of a COVID-19 outbreak in Germany resulting from a single travel-associated primary case: a case series [published online ahead of print, 2020 May 15]. Lancet Infect Dis. 2020;\$1473-3099(20)30314-5. 